\title{
Structural Transformation of Lignin from Eucalyptus during Chlorine Dioxide Bleaching
}

\author{
Chengrong Qin,, Lingzhi Huang, ${ }^{\mathrm{a}, \mathrm{b}}$ Quanfeng Lv,,${ }^{\mathrm{a}, \mathrm{b}}$ Shuangxi Nie, ${ }^{\mathrm{a}, \mathrm{b}}$ and \\ Shuangquan Yao ${ }^{\mathrm{a}, \mathrm{b}, *}$
}

\begin{abstract}
Enzymatic/mild acidolysis lignin was extracted from both unbleached and bleached eucalyptus pulp, and the difference in lignin structures was analyzed by nuclear magnetic resonance spectroscopy. The unbleached pulp lignin was chlorinated with chlorine dioxide, and the mechanism of adsorbable organic halide (AOX) formation was investigated. Chlorinated reaction products were detected by gas chromatography-mass spectrometry. There is a possibility of producing three different chlorobenzene or chlorophenol products from S/S lignin dimers that are connected with $\beta-\mathrm{O}-4$ bonds. Based on quantum chemistry theory, three reaction pathways were investigated using molecular simulation techniques. The results showed that pathway 1 possessed the lowest reaction activation energy, which made it the most favored thermodynamically. The $\beta-\mathrm{O}-4$ bond of the lignin dimer was cleaved. Following that scission, 2-chloro-3,5-dimethoxy-methyl benzene was the most likely product to be generated from the chlorination reaction of the syringyl unit. These results provide theoretical guidance for further reduction of $\mathrm{AOX}$ in chlorine dioxide bleaching.
\end{abstract}

Keywords: Lignin; Chlorine dioxide; NMR; Chlorination reaction; Reaction pathway

Contact information: a: Department of Light Industrial and Food Engineering, Guangxi University, Nanning, 530004, PR China; b: Guangxi Key Laboratory of Clean Pulp \& Papermaking and Pollution Control, Nanning 530004, PR China; *Corresponding author: yaoshuangquan@sina.cn

\section{INTRODUCTION}

Reactions with elemental chlorine $\left(\mathrm{Cl}_{2}\right)$ and related chemicals such as $\mathrm{ClO}_{2}$ have long played a major role in the bleaching of pulp fibers for the production of paper products. Chlorination can be defined as the reaction between $\mathrm{Cl}_{2}$ and the residual lignin in pulp. During chlorination, lignin is degraded into fragments that dissolve in water or a dilute alkaline solution. The lignin fragments that are dissolved are removed in the next step, since the chlorination is performed in an acidic medium (Yao et al. 2018). When using $\mathrm{Cl}_{2}$, adsorbable organic halides (AOX), which are chlorinated lignin derivatives, are found in the wastewater of pulping and papermaking enterprises. The AOX is mainly produced during chlorine dioxide bleaching (Sharma et al. 2014). Although AOX formation has been remarkably reduced by using elemental chlorine-free bleaching sequences (Liu et al. 2015), the discharge volume of pulp and paper wastewater is large and AOX is the most notable persistent organic pollutant produced from bleaching. Persistent organic pollutants display characteristics of persistent residues, bioaccumulation, high toxicity, semi-volatility, and long-distance migration (Jaacks and Staimez 2015). Therefore, total AOX emissions to the natural environment accumulate continuously and the environmental threat is increasing. AOX reduction has been made possible by process optimization, the addition of chemical additives, and pretreatment 
(Yao et al. 2017). Also, the presence of hemicellulose (Yao et al. 2017) and hexenuronic acid (Nie et al. 2015; Zhang et al. 2019) has had an effect on AOX formation. Nevertheless, the main source of AOX is the reaction between residual lignin and chlorinated bleaching agents (Nie et al. 2014). The oxidation of 1-(3,4dimethoxyphenyl)ethanol (MVA), a lignin model compound, with chlorine dioxide under simulated bleaching conditions were studied.

In biomass, the chemical structure of lignin is complex (Kim et al. 2016; Xiong et al. 2017; Xing et al. 2019) and it is associated with cellulose and hemicellulose (Lin et al. 2018; Nie et al. 2018). The separation and purification of lignin is difficult, as it easily degrades and undergoes a condensation reaction (Smith et al. 2016; Servaes et al. 2017). The introduction of enzymatic/mild acidolysis lignin (EMAL) has improved the enzymatic method of obtaining lignin (Lou and $\mathrm{Wu}$ 2011; Edmunds et al. 2017). To evaluate the inhibition effects of pseudo-lignin on the enzymatic hydrolysis of cellulose compared with lignin, EMAL was isolated from poplar with an 8-min pretreatment at $170{ }^{\circ} \mathrm{C}$ in $0.5 \% \mathrm{H}_{2} \mathrm{SO}_{4}$ (Hu et al. 2013). The results showed that the diluted acidpretreated lignin inhibited hydrolysis in the initial stage. A high yield and high lignin purity were obtained using this method, and the lignin structure was not changed compared with that of enzymatically obtained lignin. Extracted lignin is suitable for the identification of lignin structures (Constant et al. 2016; Yue et al. 2016). The structure of lignin was studied ( $\mathrm{Lu}$ et al. 2016), the main intermolecular lignin connection in wood biomass is the $\beta-\mathrm{O}-4$ bond, which accounts for approximately $50 \%$ of intermolecular connections. The constitutional unit and intermolecular connections of lignin have a great influence on the chemical activity of lignin.

This paper mainly focused on the mechanism of lignin chlorination during chlorine dioxide bleaching. Lignin was extracted from unbleached and bleached eucalyptus pulp. The structural changes to lignin during chlorine dioxide bleaching were analyzed by nuclear magnetic resonance (NMR) spectroscopy. AOX formation from the chlorination reaction of the unbleached lignin was analyzed by gas chromatography-mass spectrometry (GC-MS). Three distinct reaction pathways for AOX formation were investigated. The activation energy of each reaction was calculated based on the quantum chemistry theory. The most favorable reaction pathway was determined.

\section{EXPERIMENTAL}

\section{Materials}

The eucalyptus wood and chlorine dioxide solution were provided by a local pulp and paper mill (Guangxi, China). The chemical composition of the eucalyptus wood (five-year-old Eucalyptus urophylla), was $1.70 \%$ ash, $1.49 \%$ benzene-alcohol extract, $18.2 \%$ sodium hydroxide extract, $22.4 \%$ lignin, $51.9 \%$ cellulose, and $24.0 \%$ hemicellulose. The effective chlorine in the chlorine dioxide solution was $14.6 \%$. The content of chlorine dioxide and chlorine gas in the solution was $17.8 \mathrm{~g} / \mathrm{L}$ and $2.20 \mathrm{~g} / \mathrm{L}$, respectively. Cellulase (255 FPU/mL) was purchased from Novozymes (Copenhagen, Denmark). All of the assay reagents were obtained from Sigma (St. Louis, USA). All of the other chemicals employed in this work were purchased from Aladdin Reagent CO. LTD. (Shanghai, China). All of the chemicals used were of analytical grade. 


\section{Methods}

Cooking was conducted in a laboratorial digester that simulates a continuous digester (Greenwood Instruments, Andover, MA, USA) with six 1000-mL stainless steel cylindrical reactors. The general method consisted of $50 \mathrm{~g}$ of dry eucalyptus being added to pure water. The ratio of solid to liquid was 1:5, and 10\% sodium hydroxide (\% dry raw material) was added. The mixture was heated to $160{ }^{\circ} \mathrm{C}$ over $90 \mathrm{~min}$. Thermal insulation occurred for $60 \mathrm{~min}$ at $160{ }^{\circ} \mathrm{C}$. Then, the digester control program was stopped and the reaction was terminated.

The bleaching reaction was performed in a water bath kettle. Additionally, $10 \mathrm{~g}$ of unbleached dry pulp or lignin was mixed with pure water in a sealed polyethylene bag. The mixture concentration was $10 \%$, and the mixture was thoroughly mixed for 5 min. The $\mathrm{pH}$ of the reaction solution was adjusted to approximately 3.5 to 4 using a sulfuric acid solution. Finally, $120-\mathrm{kg} / \mathrm{tp}$ (2.0\% of $10 \mathrm{~g}$ unbleached dry pulp) (w/w) chlorine dioxide solutions were added to the mixture at $65^{\circ} \mathrm{C}$. The reaction time was $60 \mathrm{~min}$. The mixture was kneaded every 5 min during the reaction and the pulp was washed to a neutral $\mathrm{pH}$ at the end of the reaction. The reaction solution was collected (Nie et al. 2015; Yao et al. 2017).

Lignin was isolated from the unbleached and bleached eucalyptus pulp using the EMAL method (Lou and $\mathrm{Wu}$ 2011). The raw materials were pretreated with cellulases, and the volume fraction of the enzyme solution was $10 \%$. Enzymatic hydrolysis of the raw materials was performed for $72 \mathrm{~h}$ in a shaking table at $200 \mathrm{rpm}, 40{ }^{\circ} \mathrm{C}$, and a $\mathrm{pH}$ of 4.5. The enzymatically hydrolyzed crude lignin was obtained by centrifugation. The isolated crude lignin was washed with $1.4 \%$ (w/w) dilute sulfuric acid at $165{ }^{\circ} \mathrm{C}$ for 8 min. The final crude lignin was freeze-dried. Then, the crude enzymatic lignin was dispersed in $100 \mathrm{~mL}$ of a dioxane-water mixture that contained $85 \mathrm{~mL}$ of dioxane and 15 $\mathrm{mL}$ of water, which was then refluxed at $87{ }^{\circ} \mathrm{C}$ under nitrogen for $2 \mathrm{~h}$. After the reaction was completed, the mixture was filtered and the residue was washed with a neutral dioxane-water mixture to clarify the filtrate. The obtained filtrate was neutralized with sodium bicarbonate and concentrated under a reduced pressure at $35{ }^{\circ} \mathrm{C}$. A small amount of concentrated solution was slowly added to a large amount of pure water. The mixture was centrifuged after standing for $12 \mathrm{~h}$, and then the remaining solid was freeze-dried. The dried solid was purified with chromatographically pure n-hexane to remove the residual extract, and high purity EMAL was obtained.

The structural characteristics of the lignin were detected using 2D-heteronuclear single quantum coherence (HSQC)-NMR spectroscopy (Moghaddam et al. 2017). The structural changes of the lignin, bleached and unbleached, were analyzed. The basic detection methods were as follows. First, $50 \mathrm{mg}$ of EMAL were dissolved in $1 \mathrm{~mL}$ of DMSO-d6. The solvent peak of the DMSO-d6 was used as a reference point for the internal chemical shift $(\delta \mathrm{C} / \delta \mathrm{H}=39.5 / 2.49)$. Additionally, ${ }^{1} \mathrm{H}-{ }^{13} \mathrm{C}$ correlation $2 \mathrm{D}-\mathrm{HSQC}$ NMR spectra were recorded at $25{ }^{\circ} \mathrm{C}$ on a Bruker DRX-500 spectrometer (Karlsruhe, Germany). The basic method and process for ${ }^{1} \mathrm{H}-{ }^{13} \mathrm{C}$ 2D-HSQC-NMR spectroscopy were described by Moghaddam et al. (2014).

The chemical composition of the reaction solution was analyzed by GC-MS (6890-5973, Agilent Technologies, Palo Alto, CA, USA). The organic chlorides were qualitatively and quantitatively analyzed, and the solution was concentrated. The concentrate was extracted by column adsorption and $1 \mu \mathrm{L}$ of the concentrate was analyzed. The detailed operating conditions for GC-MS used in this study are described in previous studies (Nie et al. 2014; Yao et al. 2015). 
Structural models were constructed by molecular simulation techniques using the visualizer module of Materials Studio (Neotrident Technology Limited, 7.0, Beijing, China). Density functional theory (DFT) calculations were performed using the Dmol3 program (Wu et al. 2014). The double numerical plus polarization function and generalized gradient approximation functional were used for all of the geometry optimizations. The atoms of the reactants and products were matched and the reaction barrier between the reactant and transition state was used as the reaction activation energy. The transition state was analyzed by the complete linear synchronous transit (LST) and quadratic synchronous transit (QST) methods.

\section{RESULTS AND DISCUSSION}

\section{Response Analysis}

The lignin extracted from both the unbleached and bleached eucalyptus pulp was analyzed by 2D-HSQC-NMR in the gel state according to previously published methods (Wen et al. 2013; Ando et al. 2017). The functional groups and basic structural units of the lignin and the bonding of basic structural units were depicted in the HSQC spectra (Fig. 1). The assignments of the main signals in Fig. 1 for the unbleached pulp lignin are listed in Table 1. The peak assignments were based on previous publications (del Río et al. 2015; Wen et al. 2015).

Table 1. Assignment of Main Signals in NMR Spectra of Unbleached Pulp Lignin

\begin{tabular}{|c|c|c|}
\hline $\begin{array}{l}\text { Serial } \\
\text { Number }\end{array}$ & Chemical Shift (ppm) & Structure Assignment \\
\hline 1 & $56.17 / 3.72$ & Methoxy (MeO) \\
\hline 2 & $57.92 / 3.71$ & $\mathrm{C}_{\gamma}-\mathrm{H} \gamma$ of $\beta-\mathrm{O}-4$ (Aү) \\
\hline 3 & $59.02 / 3.71$ & $\mathrm{C}_{\gamma}-\mathrm{H} \gamma$ of $\beta-\mathrm{O}-4(\mathrm{A \gamma})$ \\
\hline 4 & $61.3 / 3.80$ & $\mathrm{C}_{-}-\mathrm{H} \gamma$ of PCA (CY) \\
\hline 5 & $62.9 / 4.22$ & $\mathrm{C} \alpha-\mathrm{H \alpha}$ of $\beta-\mathrm{O}-4\left(\mathrm{~A}^{\prime} \gamma\right)$ \\
\hline 6 & $64.07 / 4.10$ & $\begin{array}{c}\mathrm{C}_{\gamma}-\mathrm{Hy} \text { of the end group of unacetylated } \mathrm{p}- \\
\text { Coumaryl alcohol (ly) }\end{array}$ \\
\hline 7 & $104.55 / 6.71$ & $\mathrm{C}_{2}-\mathrm{H}_{2}$ and $\mathrm{C}_{6}-\mathrm{H}_{6}$ of $\mathrm{S}$-unit $\left(\mathrm{S}_{2,6}\right)$ \\
\hline 8 & $115.11 / 6.70$ & $\mathrm{C}_{5}-\mathrm{H}_{5}$ of $\mathrm{G}$-unit $\left(\mathrm{G}_{5}\right)$ \\
\hline
\end{tabular}

Cross-signals of methoxyl groups and $\beta-\mathrm{O}-4$ substructures were present in all, but two lignin samples. The $\mathrm{C} \gamma / \mathrm{H} \gamma$ correlation signals of the $\beta-\mathrm{O}-4$ substructures $(\mathrm{A} \gamma)$ and the $\mathrm{C} \alpha / \mathrm{H} \alpha$ correlation signals of the $\beta-\mathrm{O}-4$ structures $\left(\mathrm{A}^{\prime} \gamma\right)$ were detected in all, but two lignin samples. Weak signals were observed in the bleached pulp lignin at $\delta_{\mathrm{C}} / \delta_{\mathrm{H}}$ signals of 57.92/3.71, 59.02/3.71, and 62.9/4.22 for A $\gamma$ and A' $\gamma$. Signals for A $\gamma$ and A' $\gamma$ in the lignin extracted from the bleached pulp were attenuated, which indicated that the $\beta-\mathrm{O}-4$ bond of the lignin constitutional unit was cleaved during the chlorine dioxide reaction.

Eucalyptus lignin is a copolymer primarily composed of guaiacyl (G) and syringyl $(\mathrm{S})$ units. In the HSQC spectrum of the bleached pulp, signals for $\mathrm{S}$ units $\left(\mathrm{S}_{2,6}\right)$ and methoxy (OMe) groups were barely observed. This was mainly because of the oxidizing reaction of the $S$ unit structure during the bleaching process. Most lignin is oxidized by chlorine dioxide, and little is derivitized. The signals for $\mathrm{S}_{2,6}$ and OMe were obscured or offset by the partial substituents that were introduced. The intensities of the $\mathrm{C} \gamma, \mathrm{G}_{5}$, and $\mathrm{I} \gamma$ signals were lower in the HSQC spectrum of the unbleached pulp, which 
indicated the existence of residual lignin following the bleaching process. The results showed that the $\mathrm{S} / \mathrm{S}$ lignin dimer, which was connected by a $\beta-\mathrm{O}-4$ bond in the unbleached pulp, participated in the substitution reactions to produce organic chlorides during chlorine dioxide bleaching.

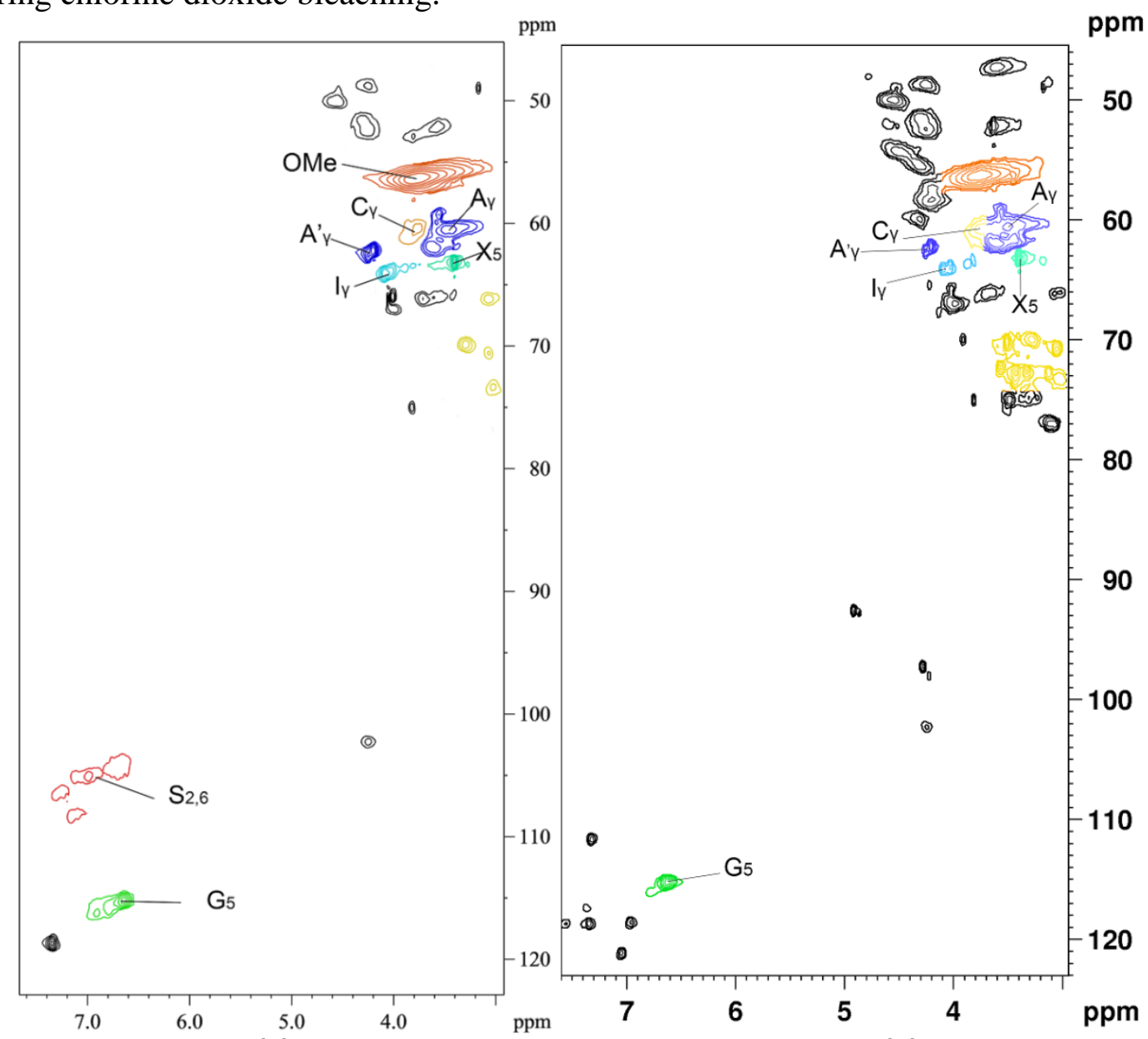

(a)

(b)

Fig. 1. 2D-HSQC NMR spectra of the EMAL extracted from the (a) unbleached pulp lignin and (b) bleached pulp lignin

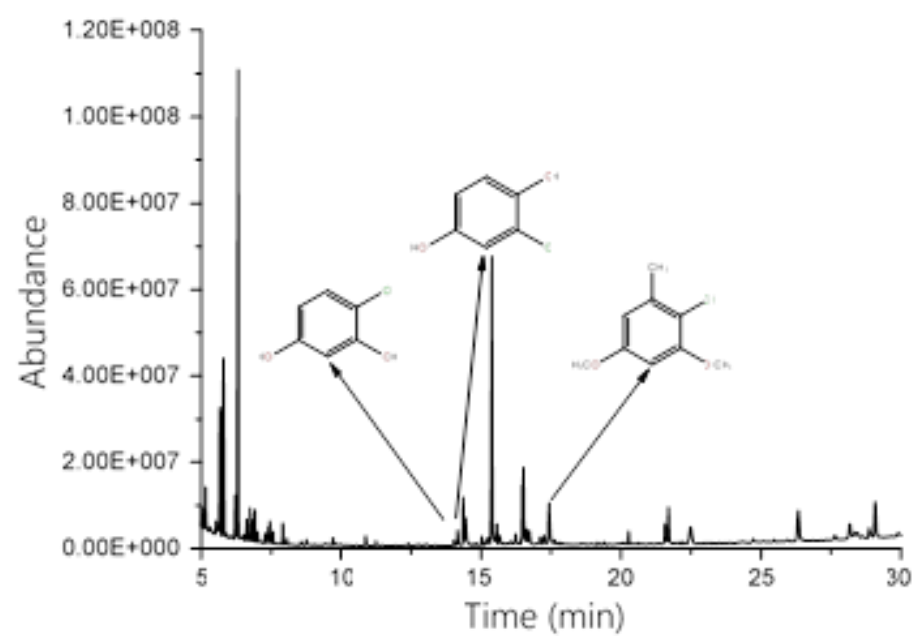

Fig. 2. GC-MS graph of the reaction solution 
The residual lignin in unbleached pulp is the main source for AOX formation. To understand the mechanism of AOX formation, the organic chlorides produced by the reaction of lignin and chlorine dioxide need to be analyzed. The GC-MS graph of the bleaching effluent after chlorine dioxide bleaching is shown in Fig. 2.

Table 2. Main Organic Chlorides of the Reaction Solution

\begin{tabular}{cccc}
\hline No. & $\begin{array}{c}\text { Retention Time } \\
(\mathrm{min})\end{array}$ & $\begin{array}{c}\text { Relative Content } \\
(\%)\end{array}$ & Organic Chloride \\
\hline 1 & 5.51 & 0.12 & 1,1,3,3-Tetrachloroacetone \\
2 & 6.46 & 0.09 & 1,4-Dichloro-2-butanol \\
3 & 13.38 & 0.13 & 4-Chlororesorcinol \\
4 & 13.42 & 0.12 & 2-Chloro-1,4-benzenediol \\
5 & 16.62 & 0.35 & 2-Chloro-3,6-dihydroxy-methyl benzoate \\
6 & 16.73 & 0.30 & 2-Chloro-5-methoxyl-1-naphthol \\
7 & 17.10 & 0.35 & 2-Chloro-3,5-dimethoxy-methyl benzene \\
8 & 17.25 & 0.19 & 1,1-Dichloro-1,2-butadiene \\
\hline
\end{tabular}

The organic chlorides identified by GC-MS in the chlorine dioxide bleaching effluent are shown in Table 2. AOX comprised eight categories. The highest concentrated organic chlorides were 2-chloro-3,6-dihydroxy-methyl benzoate (16.62 $\mathrm{min})$ and 2chloro-3,5-dimethoxy-methyl benzene $(17.10 \mathrm{~min})$. The lowest concentrated organic chloride was 1,4-dichloro-2-butanol (6.46 $\mathrm{min})$. The lignin had a ring-opening reaction during oxidation between the lignin and chlorine dioxide (Behin and Zeyghami 2009). A substitution reaction occurred between the chain molecule and free chlorine in the solution. Then, 1,4-dichloro-2-butanol was produced. The organic chlorides that belong to the chlorobenzene or chlorophenol categories were 4-chlororesorcinol (13.38 $\mathrm{min})$, 2chloro-1,4-benzenediol (13.42 $\mathrm{min}$ ), and 2-chloro-3,5-dimethoxy-methyl benzene. These chlorobenzenes and chlorophenols constitute more than half of the total organic chlorides. This finding was consistent with those of Yao et al. (2017).

Figure 1 shows that the unbleached pulp lignin mainly consisted of $S$ units connected with $\beta-\mathrm{O}-4$ bonds. The main fracture mode was $\beta-\mathrm{O}-4$ bond cleavage during chlorine dioxide bleaching. Therefore, the S/S lignin dimer (connected by a $\beta-\mathrm{O}-4$ bond) was the main source for AOX formation. The S/S lignin dimer is a natural compound; it is a fragment of a lignin macromolecule. Considering that the constitutional $\mathrm{G}$ unit was present in the bleached pulp lignin, it was more likely that the $S$ unit was involved in chlorination. Based on the above conclusions, the $\beta-\mathrm{O}-4$ bond of the unbleached pulp lignin was cleaved and the $S$ unit participated in a chlorination reaction with hypochlorous acid during chlorine dioxide bleaching.

Based on the relative stability of the benzene ring, the chlorinated products from the reaction between the $\mathrm{S}$ unit and chlorine dioxide should contain the benzene ring structure, such as in chlorobenzene or chlorophenol. The main chlorinated products of the $\mathrm{S} / \mathrm{S}$ dimer determined by GC-MS analysis were 2-chloro-3,5-dimethoxy-methyl benzene, 2-chloro-1,4-benzenediol, and 4-chlororesorcinol (Fig. 2). Therefore, there were three reaction AOX formation pathways between the unbleached pulp lignin and chlorine dioxide. These results are shown in Fig. 3. 


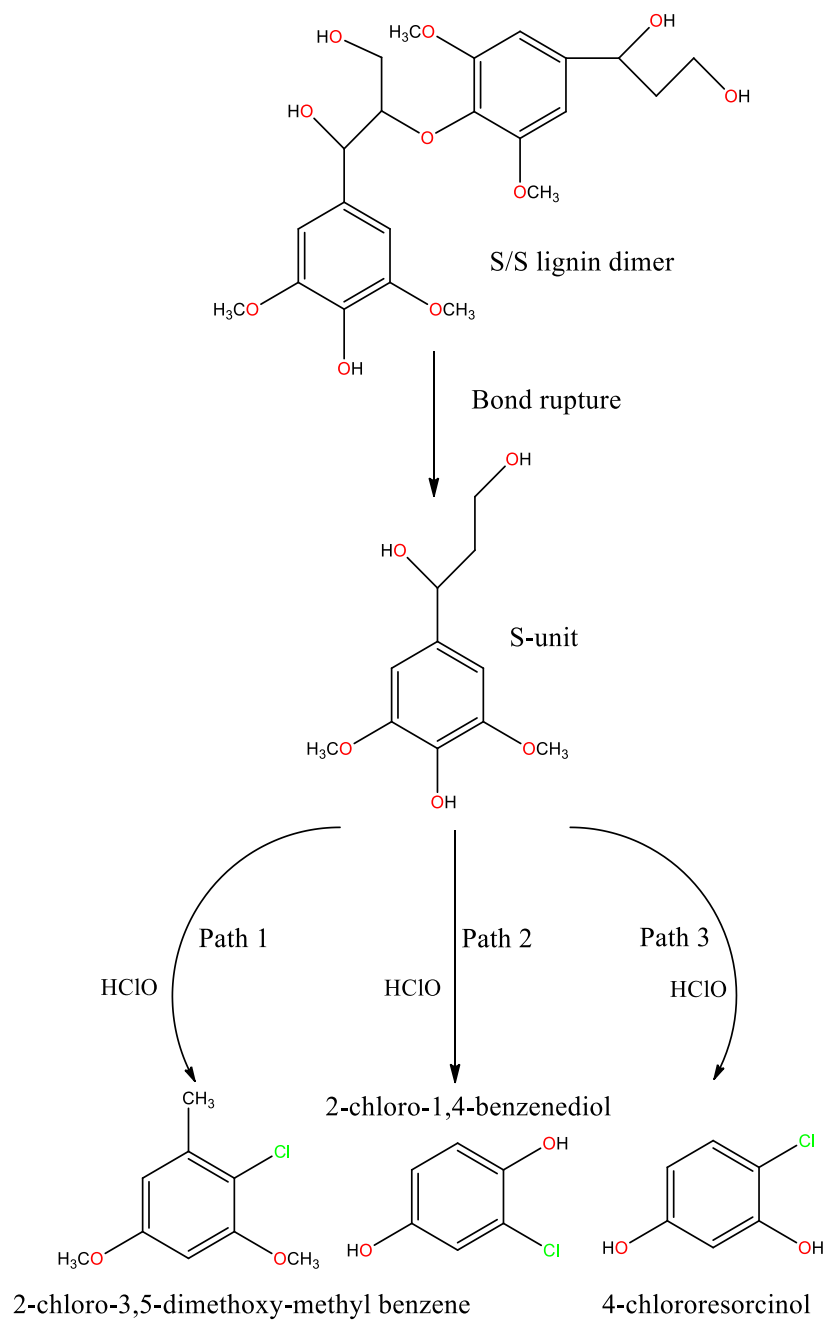

Fig. 3. Suggested reaction pathways

\section{Molecular Orbital Analysis}

The lowest unoccupied molecular orbital (LUMO) and highest occupied molecular orbital (HOMO) of the S/S lignin dimer molecule model were calculated and analyzed (Sworakowski et al. 2016).

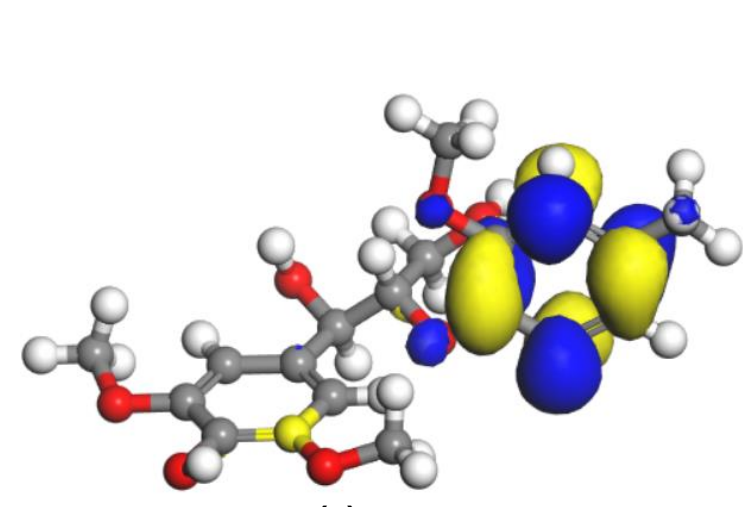

(a)

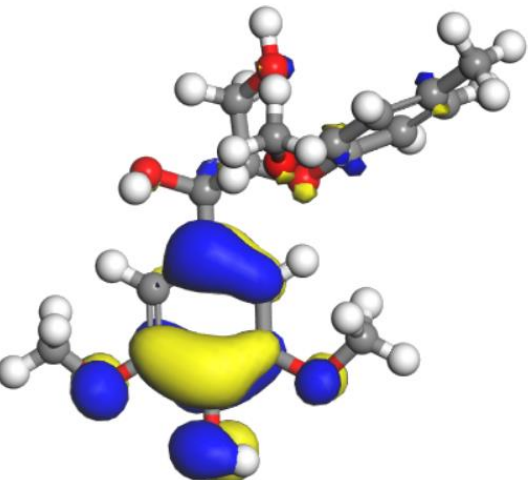

(b)

Fig. 4. Orbital of the HOMO (a) and LUMO (b) in the S/S lignin dimer 
The HOMO was mainly distributed on the $\mathrm{C}_{1}, \mathrm{C}_{2}, \mathrm{C}_{3}, \mathrm{C}_{4}, \mathrm{C}_{5}$, phenolic hydroxyl groups, and methoxy groups of the $\mathrm{S}$ unit (Fig. 4). The electrons of these atoms are easily excited. This indicated that a facile nucleophilic reaction can occur in the benzene, phenol hydroxyl, and two methoxy groups. The energy of the HOMO formation was found to be $-0.180 \mathrm{eV}$. The LUMO was mainly distributed on the benzene carbons, methoxy groups, and methyl groups of the $S$ unit, and its energy was found to be -0.061 $\mathrm{eV}$. The reactivity of $\mathrm{S}$ units is higher because of the increased number of methoxy groups (Kim et al. 2017). The electrons on the HOMO can be transferred to the neighboring carbon atoms, and substitution reactions can occur at the $\mathrm{C}-\mathrm{C}$ bonds of the $\mathrm{S}$ unit because of the weakening of the $\mathrm{C}-\mathrm{OH}$ and $\mathrm{C}-\mathrm{OCH}_{3}$ bonds. The difference in orbital energy between the HOMO and LUMO formations was $0.119 \mathrm{eV}$, which indicated that the $\beta-\mathrm{O}-4$ bond of the S/S lignin dimer was relatively unstable. The reaction of the Slignin and chlorine dioxide was favored as the $S$ unit exhibited a higher reactivity. These observations verified the conclusions from the NMR analysis of the lignin.

In the basic structural unit of lignin, the reactivity of the S-lignin is the highest (Jongerius et al. 2013). The HOMO and LUMO of the S unit molecular models were calculated and analyzed to better understand the reactivity of this functional group. Figure 5 shows that the HOMO was mainly distributed on the $\mathrm{C}_{1}, \mathrm{C}_{3}, \mathrm{C}_{4}, \mathrm{C}_{5}, \mathrm{C}_{6}$, phenolic hydroxyl groups, and methoxy groups of the $\mathrm{S}$ unit. These carbon atoms tend to lose electrons, and the associated functional groups, e.g., phenolic hydroxyl and methoxy groups, were replaced. The energies of the HOMO and LUMO were found to be -0.189 $\mathrm{eV}$ and $-0.066 \mathrm{eV}$, respectively. The difference in the orbital energy was $0.123 \mathrm{eV}$, which was greater than that of the S/S lignin dimer. This indicated that the reactivity of the $S$ unit was greater than that of the $\mathrm{S} / \mathrm{S}$ lignin dimer. The branched chain of $\mathrm{C}_{1}$ was easy to break during the reaction between an $\mathrm{S}$ unit and chlorine dioxide. Chlorobenzene or chlorophenol was produced when a chlorine substitution reaction occurred at $\mathrm{C}_{2}$. The methoxy groups on $\mathrm{C}_{3}$ and $\mathrm{C}_{5}$ were removed, and hydroxyl addition reactions occurred on these active carbon atoms. Additionally, the hydroxyl group on $\mathrm{C}_{4}$ was removed. The results of the GC-MS analysis were verified by this data.

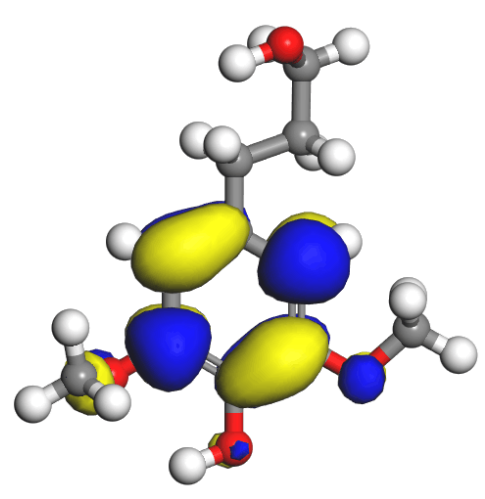

(a)

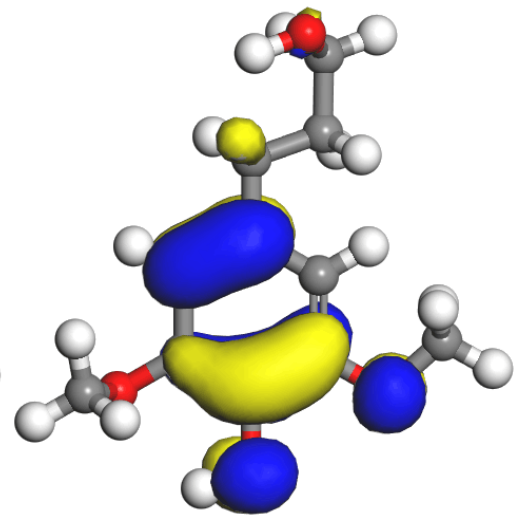

(b)

Fig. 5. Orbital of the HOMO (a) and LUMO (b) in an S unit

\section{Reaction Pathway Analysis}

Reaction pathway 1

The HOMO and LUMO formations were distributed on $\mathrm{C}_{1}$ and $\mathrm{C}_{4}$ of the $\mathrm{S}$ unit. This meant that $\mathrm{C}_{1}$ and $\mathrm{C}_{4}$ can easily gain and lose electrons. The branched chain of $\mathrm{C}_{1}$ was easy to break, and when it was broken, $\mathrm{C} \alpha$ was retained. An elimination reaction 
occurred at $\mathrm{C}_{4}$, which removed the phenolic hydroxyl group. The LUMO was also distributed on $\mathrm{C}_{2}$, which allowed this carbon to more easily gain electrons. The chlorine substitution reaction occurred at $\mathrm{C}_{2}$, where 2-chloro-3,5-dimethoxy-methyl benzene was produced. Acetic acid was produced by the reductive elimination of the $\beta$-hydroxy groups on the propanoid chain of the $\mathrm{S}$ unit. The para-hydroxy group was removed to form water molecules. These results are shown in Fig. 3.

The DFT was used to propose a mechanism for reaction pathway 1. Models of the intermediates in reaction pathway 1 were created using the visualizer module in Materials Studio. All of the atoms were matched after the structures of the reactants and products were geometrically optimized. The reaction transition state (TS) was determined by LST/QST, while the activation energy and heat of reaction were also obtained. The change curve of the path coordinate of energy $v s$. LST, QST, and conjugate gradient is shown in Fig. 6.

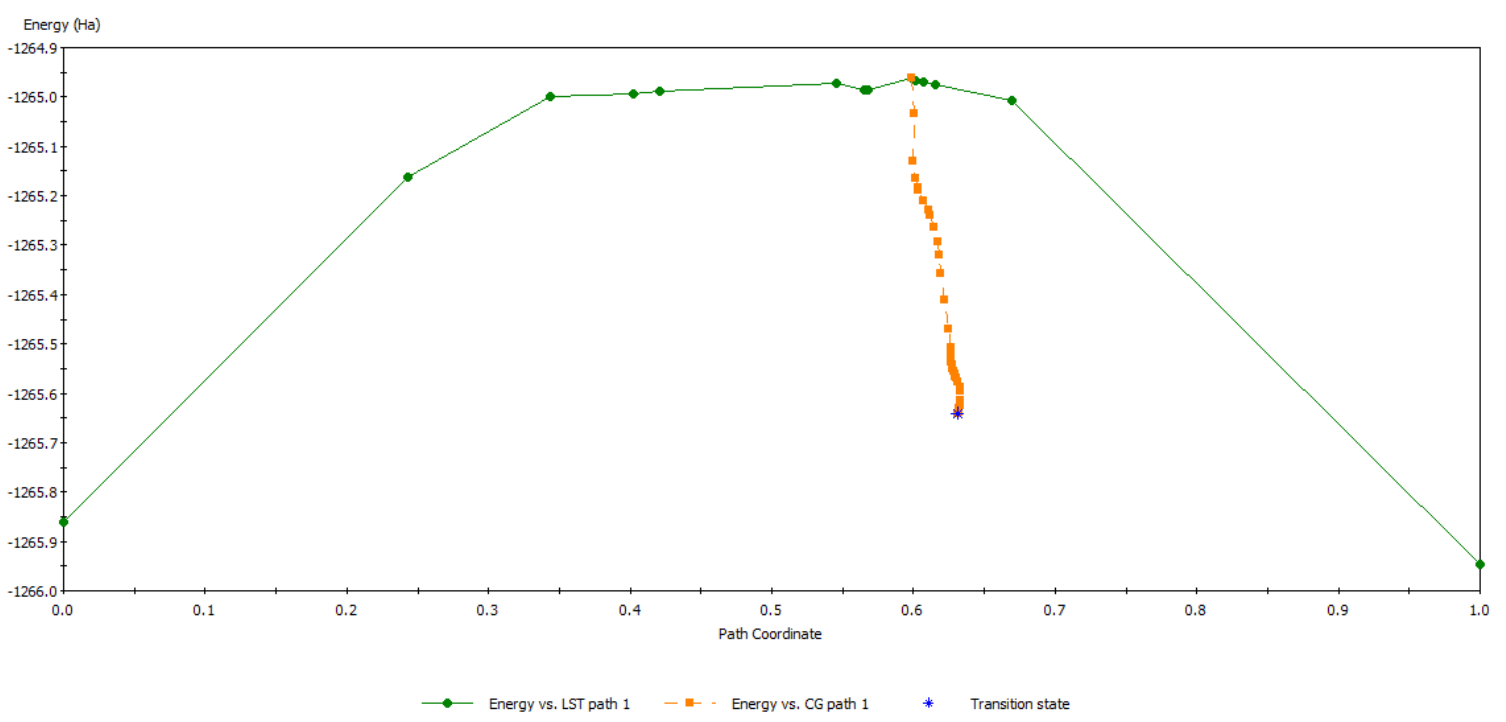

Fig. 6. Transition state of reaction pathway 1

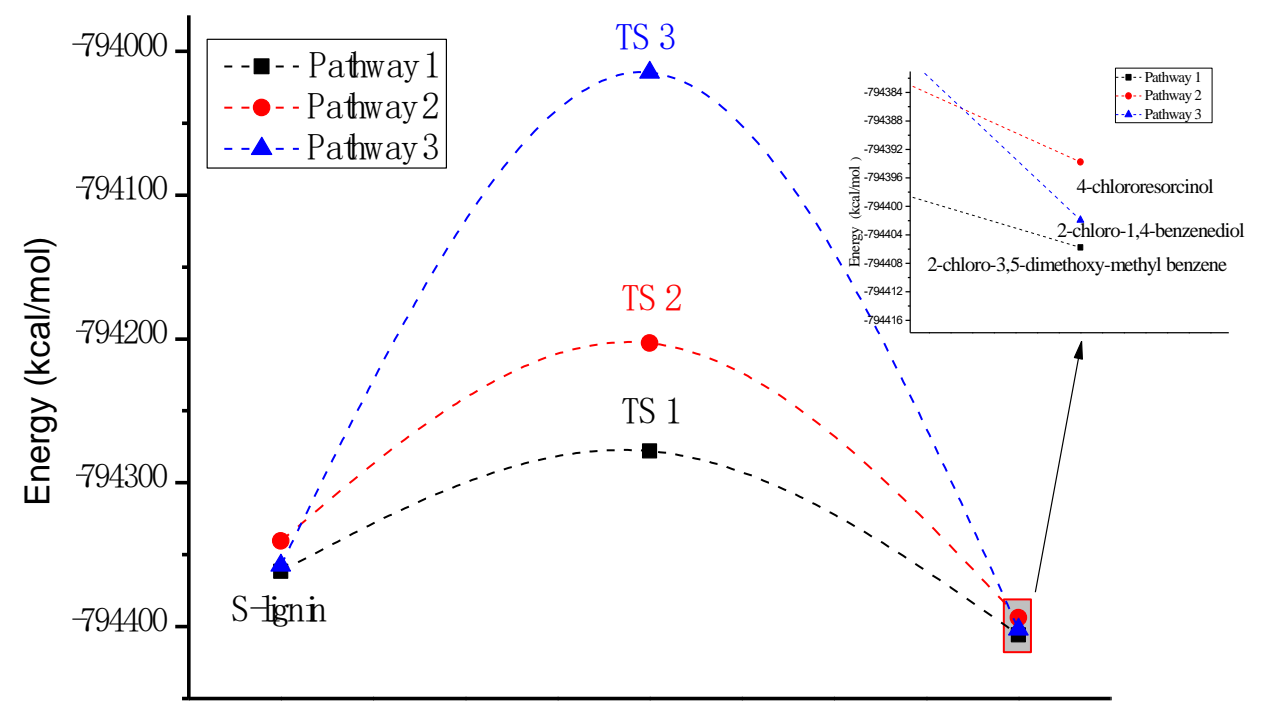

Fig. 7. Reaction pathways and energies of organic chloride formation 
The transient search process was monitored. The change curve of the path coordinate showed that there was one intermediate product in pathway 1 . This also meant that $\mathrm{C}_{1}, \mathrm{C}_{2}$, and $\mathrm{C}_{4}$ active site free radicals were formed simultaneously. The energy of pathway 1 is shown in Fig. 7. The energy of the reactant and product were -794361.52 $\mathrm{kcal} / \mathrm{mol}$ and $-794405.76 \mathrm{kcal} / \mathrm{mol}$, respectively. The energy of TS 1 (energy saddle point) was $-794278.00 \mathrm{kcal} / \mathrm{mol}$. The activation energy $(\Delta E)$ of pathway 1 was 83.75 $\mathrm{kcal} / \mathrm{mol}$. The heat of reaction $(\Delta H)$ was $-44.23 \mathrm{kcal} / \mathrm{mol}$. This showed that reaction pathway 1 was exothermic, with an overall $\Delta H$ of less than 0 .

\section{Reaction pathway 2}

The HOMO was distributed on $\mathrm{C}_{1}, \mathrm{C}_{3}$, and $\mathrm{C}_{5}$ of the $\mathrm{S}$ unit. The branched chain of $\mathrm{C}_{1}$ was removed as a whole. Elimination reactions occurred at $\mathrm{C}_{3}$ and $\mathrm{C}_{5}$, and the methoxy groups were removed. The LUMO was distributed on $\mathrm{C}_{1}$. The hydroxyl group was connected to $\mathrm{C}_{1}$ after the branched chain was removed. The LUMO was distributed on $\mathrm{C}_{2}$, which was the location of the chlorine substitution reaction. During this reaction, 2-chloro-1,4-benzenediol was produced. Additionally, methylacetic acid was produced by the reductive elimination of the $\alpha$-hydroxy groups on the propanoid chain of the $S$ unit. These results are shown in Fig. 3.

Reaction pathway 2 was simulated using the same method as reaction pathway 1 . The results are shown in Fig. 8. The change curve of the path coordinate showed that there were five intermediate products in pathway 2 . This also meant that $\mathrm{C}_{1}, \mathrm{C}_{2}, \mathrm{C}_{3}$, and $\mathrm{C}_{5}$ active site free radicals were formed successively. Branched-chain cleavage and hydroxyl addition reaction of $\mathrm{C}_{1}$ occurred successively. This was consistent with the process analysis of pathway 2. Figure 7 shows TS 2 and the energy of pathway 2. The energy of the reactant and product was $-794340.43 \mathrm{kcal} / \mathrm{mol}$ and $-794393.77 \mathrm{kcal} / \mathrm{mol}$, respectively. The energy of TS 2 (energy saddle point) was $-794203.01 \mathrm{kcal} / \mathrm{mol}$. The $\Delta E$ of pathway 2 was $137.66 \mathrm{kcal} / \mathrm{mol}$. The $\Delta H$ was $-53.74 \mathrm{kcal} / \mathrm{mol}$. This showed that pathway 2 was exothermic, as the $\Delta H$ was less than 0 . Comparing the $\Delta E$ of pathways 1 and 2 , the $\Delta E$ of pathway 1 was smaller, which meant that pathway 1 was more favorable than pathway 2 .

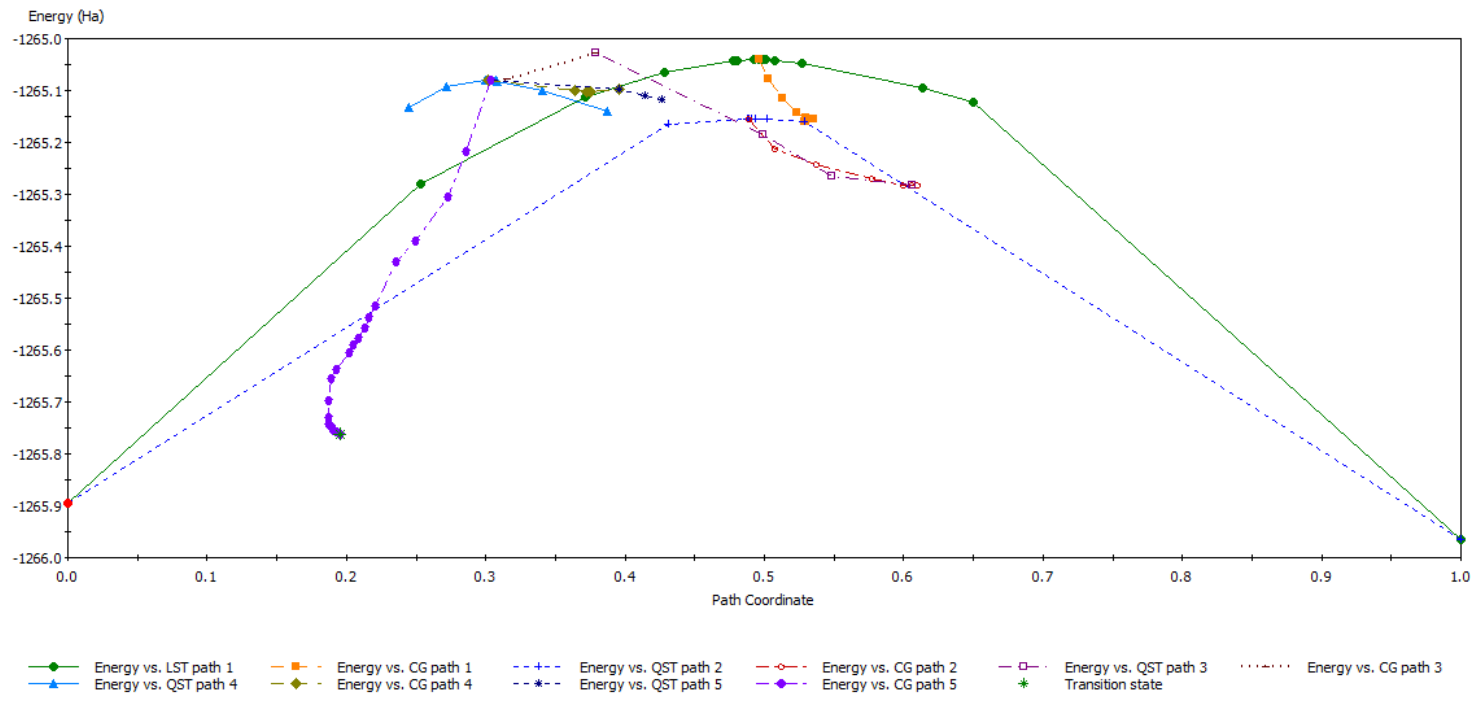

Fig. 8. Transition state of reaction pathway 2 


\section{Reaction pathway 3}

The HOMO was distributed on $\mathrm{C}_{1}, \mathrm{C}_{3}, \mathrm{C}_{4}$, and $\mathrm{C}_{5}$ of the $\mathrm{S}$ unit. The branched chain of $\mathrm{C}_{1}$ was removed as a whole. The elimination reaction occurred on $\mathrm{C}_{3}, \mathrm{C}_{4}$, and $\mathrm{C}_{5}$, which removed the methoxy and phenolic hydroxyl groups. The LUMO was distributed on $\mathrm{C}_{2}, \mathrm{C}_{3}$, and $\mathrm{C}_{5}$. The hydroxyl groups were grafted after the methoxy groups were removed from $\mathrm{C}_{3}$ and $\mathrm{C}_{5}$. The chlorine substitution reaction occurred on $\mathrm{C}_{2}$, and 4chlororesorcinol was produced. Methylacetic acid was produced by the reductive elimination of the $\alpha$-hydroxy groups on the propanoid chain of the $S$ unit. The parahydroxy group was removed to form water molecules and the results are shown in Fig. 3.

Pathway 3 was simulated using the same method as reaction pathway 1 . The results are shown in Fig. 9. The change curve of the path coordinate shows that there were two intermediate products in pathway 3 . This also meant that $\mathrm{C}_{1}, \mathrm{C}_{3}, \mathrm{C}_{4}$, and $\mathrm{C}_{5}$ active site free radicals were formed simultaneously. The hydroxyl addition reactions of $\mathrm{C}_{3}$ and $\mathrm{C}_{5}$ occurred successively. Figure 7 shows TS 3 and the energy of pathway 3 . The energy of the reactant and product were $-794357.36 \mathrm{kcal} / \mathrm{mol}$ and $-794401.92 \mathrm{kcal} / \mathrm{mol}$, respectively. The energy of TS 3 (energy saddle point) was $-794014.74 \mathrm{kcal} / \mathrm{mol}$. The $\Delta E$ of pathway 3 was $342.70 \mathrm{kcal} / \mathrm{mol}$. The $\Delta H$ was $-44.82 \mathrm{kcal} / \mathrm{mol}$. This showed that pathway 3 was exothermic, as $\Delta H$ was less than 0 . Comparing the $\Delta E$ of pathways 1,2 , and 3, pathway 1 had the lowest activation energy, which meant that pathway 1 was more favorable than pathway 2 or 3 .

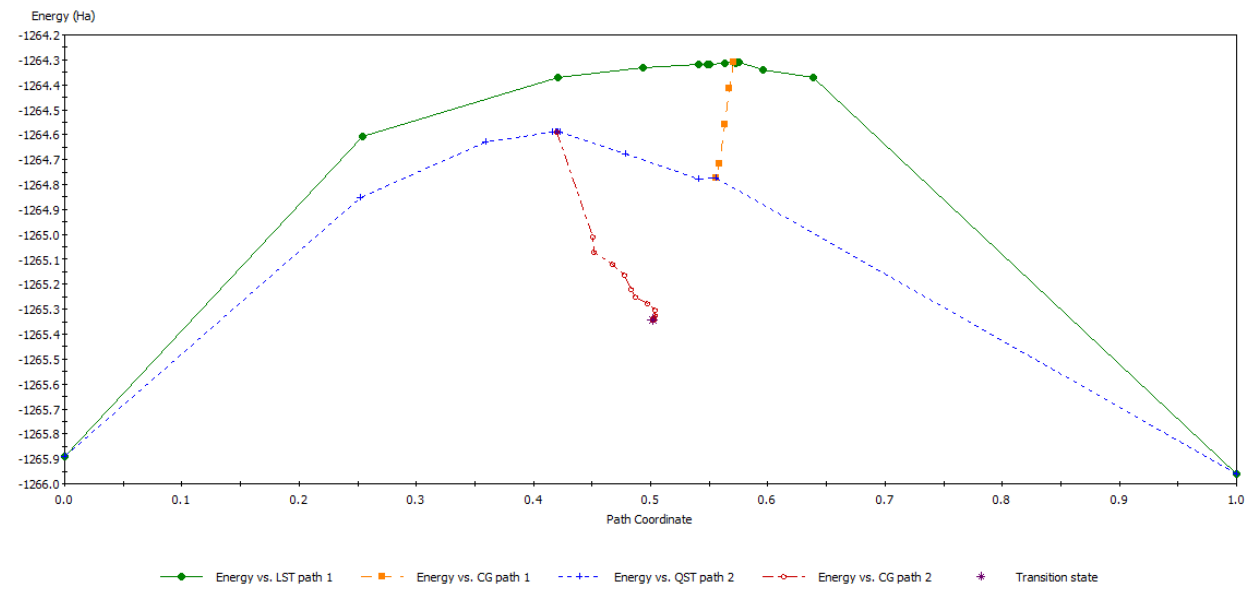

Fig. 9. Transition state of reaction pathway 3

The highest organic chloride content detected was 2-chloro-3,5-dimethoxy-methyl benzene, which was produced by the reaction of the unbleached lignin and chlorine dioxide. Based on the contents of the reaction products, reaction pathway 1 was the most favorable. This finding was consistent with the conclusions of the molecular modeling calculations. These results introduce a new methodology to study the complex chemical reaction system of AOX produced by lignin and chlorine dioxide.

\section{CONCLUSIONS}

1. Enzymatic/mild acidolysis lignin was extracted from both unbleached and bleached eucalyptus pulp. The $\beta-\mathrm{O}-4$ bond of the $\mathrm{S} / \mathrm{S}$ lignin dimer, which came from the 
unbleached pulp, was cleaved during $\mathrm{ClO}_{2}$ bleaching. The $\mathrm{S}$ unit was the main reactant from which organic chlorides were produced during the bleaching process.

2. Chlorinated products contained three kinds of chlorobenzenes or chlorophenols, of which 2-chloro-3,5-dimethoxy-methyl benzene had the highest content. Three chlorination pathways were speculated. The pathways were calculated using molecular simulation technology. Pathway 1 was found to be optimal because it had the lowest activation energy. The compound 2-chloro-3,5-dimethoxy-methyl benzene was most easily produced between the reaction of the $\mathrm{S}$ unit and chlorine dioxide.

\section{ACKNOWLEDGMENTS}

This project was sponsored by the National Natural Science Foundation of China (Grant Nos. 31760192 and 21466004) and supported by the Guangxi Natural Science Foundation of China (Grant No. 2016GXNSFBA380234).

\section{REFERENCES CITED}

Ando, D., Nakatsubo, F., and Yano, H. (2017). "Acetylation of ground pulp: Monitoring acetylation via HSQC-NMR spectroscopy," ACS Sustain. Chem. Eng. 5(2), $1755-$ 1762. DOI: 10.1021/acssuschemeng.6b02518

Behin, J., and Zeyghami, M. (2009). "Dissolving pulp from corn stalk residue and waste water of Merox unit," Chem. Eng. J. 152(1), 26-35. DOI: 10.1016/j.cej.2009.03.024

Constant, S., Wienk, H. L. J., Frissen, A. E., de Peinder, P., Boelens, R., van Es, D. S., Grisel, R. J. H., Weckhuysen, B. M., Huijgen, W. J. J., and Gosselink, R. J. A. (2016). "New insights into the structure and composition of technical lignins: A comparative characterisation study," Green Chem. 18(9), 2651-2665. DOI: 10.1039/C5GC03043A

Del Río, J. C., Lino, A. G., Colodette, J. L., Lima, C. F., Gutiérrez, A., Martínez, Á. T., Lu, F., Ralph, J., and Rencoret, J. (2015). "Differences in the chemical structure of the lignins from sugarcane bagasse and straw," Biomass Bioenerg. 81, 322-338. DOI: 10.1016/j.biombioe.2015.07.006

Edmunds, C. W., Peralta, P., Kelley, S. S., Chiang, V. L., Sharma-Shivappa, R. R., Davis, M. F., Harman-Ware, A. E., Sykes, R. W., Gjersing, E., Cunningham, M. W., et al. (2017). "Characterization and enzymatic hydrolysis of wood from transgenic Pinus taeda engineered with syringyl lignin or reduced lignin content," Cellulose 24(4), 1901-1914. DOI: $10.1007 / \mathrm{s} 10570-017-1231-\mathrm{z}$

$\mathrm{Hu}, \mathrm{F}$., Jung, S., and Ragauskas, A. (2013). "Impact of pseudolignin versus dilute acidpretreated lignin on enzymatic hydrolysis of cellulose," ACS Sustain. Chem. Eng. 1(1), 62-65. DOI: $10.1021 / \mathrm{sc} 300032 \mathrm{j}$

Jaacks, L. M., and Staimez, L. R. (2015). "Association of persistent organic pollutants and non-persistent pesticides with diabetes and diabetes-related health outcomes in Asia: A systematic review," Environ. Int. 76, 57-70. DOI:

10.1016/j.envint.2014.12.001

Jongerius, A. L., Bruijnincx, P. C. A., and Weckhuysen, B. M. (2013). "Liquid-phase reforming and hydrodeoxygenation as a two-step route to aromatics from lignin," Green Chem. 15(11), 3049-3056. DOI: 10.1039/C3GC41150H 
Kim, M., Son, D., Choi, J.-W., Jae, J., Dong, J. S., Ha, J.-M., and Lee, K.-Y. (2017). "Production of phenolic hydrocarbons using catalytic depolymerization of empty fruit bunch (EFB)-derived organosolv lignin on H $\beta$-supported Ru," Chem. Eng. J. 309, 187-196. DOI: 10.1016/j.cej.2016.10.011

Kim, S., Oh, S., Lee, J., Roh, H.-g., and Park, J. (2016). "Changes of lignin molecular structures in a modification of kraft lignin using acid catalyst," Materials 9(8), 657671. DOI: $10.3390 / \mathrm{ma} 9080657$

Lin, X., Wu, Z., Zhang, C., Liu, S., and Nie, S. (2018). "Enzymatic pulping of lignocellulosic biomass," Ind. Crop. Prod. 120, 16-24. DOI: 10.1016/j.indcrop.2018.04.033

Liu, J., Li, M., Luo, X., Chen, L., and Huang, L. (2015). "Effect of hot-water extraction (HWE) severity on bleached pulp based biorefinery performance of eucalyptus during the HWE-Kraft-ECF bleaching process," Bioresource Technol. 181, 183-190. DOI: 10.1016/j.biortech.2015.01.055

Lou, R., and Wu, S.-B. (2011). "Products properties from fast pyrolysis of enzymatic/ mild acidolysis lignin," Appl. Energ. 88(1), 316-322. DOI: 10.1016/j.apenergy.2010.06.028

Lu, J., Wang, M., Zhang, X., Heyden, A., and Wang, F. (2016). " $\beta-O-4$ bond cleavage mechanism for lignin model compounds over Pd catalysts identified by combination of first-principles calculations and experiments," ACS Catal. 6(8), 5589-5598. DOI: 10.1021/acscatal.6b00502

Moghaddam, L., Rencoret, J., Maliger, V. R., Rackemann, D. W., Harrison, M. D., Gutierrez, A., del Rio, J. C., and Doherty, W. O. S. (2017). "Structural characteristics of bagasse furfural residue and its lignin component. A NMR, Py-GC/MS, and FTIR study," ACS Sustain. Chem. Eng. 5(6), 4846-4855. DOI:

10.1021/acssuschemeng. $7 \mathrm{~b} 00274$

Moghaddam, L., Zhang, Z., Wellard, R. M., Bartley, J. P., O’Hara, I. M., and Doherty, W. O. S. (2014). "Characterisation of lignins isolated from sugarcane bagasse pretreated with acidified ethylene glycol and ionic liquids," Biomass Bioenerg. 70, 498-512. DOI: 10.1016/j.biombioe.2014.07.030

Nie, S., Liu, X., Wu, Z., Zhan, L., Yin, G., Yao, S., Song, H., and Wang, S. (2014). "Kinetics study of oxidation of the lignin model compounds by chlorine dioxide," Chem. Eng. J. 241, 410-417. DOI: 10.1016/j.cej.2013.10.068

Nie, S., Wang, S., Qin, C., Yao, S., Ebonka, J. F., Song, X., and Li, K. (2015). "Removal of hexenuronic acid by xylanase to reduce adsorbable organic halides formation in chlorine dioxide bleaching of bagasse pulp," Bioresource Technol. 196, 413-417. DOI: 10.1016/j.biortech.2015.07.115

Nie, S., Zhang, K., Lin, X., Zhang, C., Yan, D., Liang, H., and Wang, S. (2018). "Enzymatic pretreatment for the improvement of dispersion and film properties of cellulose nanofibrils," Carbohyd. Polym. 181, 1136-1142. DOI: 10.1016/j.carbpol.2017.11.020

Servaes, K., Varhimo, A., Dubreuil, M., Bulut, M., Vandezande, P., Siika-aho, M., Sirviö, J., Kruus, K., Porto-Carrero, W., and Bongers, B. (2017). "Purification and concentration of lignin from the spent liquor of the alkaline oxidation of woody biomass through membrane separation technology," Ind. Crop. Prod. 106, 86-96. DOI: 10.1016/j.indcrop.2016.10.005

Sharma, A., Thakur, V. V., Shrivastava, A., Jain, R. K., Mathur, R. M., Gupta, R., and Kuhad, R. C. (2014). "Xylanase and laccase based enzymatic kraft pulp bleaching 
reduces adsorbable organic halogen (AOX) in bleach effluents: A pilot scale study," Bioresource Technol. 169, 96-102. DOI: 10.1016/j.biortech.2014.06.066

Smith, M. D., Mostofian, B., Cheng, X., Petridis, L., Cai, C. M., Wyman, C. E., and Smith, J. C. (2016). "Cosolvent pretreatment in cellulosic biofuel production: Effect of tetrahydrofuran-water on lignin structure and dynamics," Green Chem. 18(5), 1268-1277. DOI: 10.1039/C5GC01952D

Sworakowski, J., Lipiński, J., and Janus, K. (2016). "On the reliability of determination of energies of HOMO and LUMO levels in organic semiconductors from electrochemical measurements. A simple picture based on the electrostatic model," Org. Electron. 33, 300-310. DOI: 10.1016/j.orgel.2016.03.031

Wen, J.-L., Sun, S.-L., Yuan, T.-Q., and Sun, R.-C. (2015). "Structural elucidation of whole lignin from Eucalyptus based on preswelling and enzymatic hydrolysis," Green Chem. 17(3), 1589-1596. DOI: 10.1039/C4GC01889C

Wen, J.-L., Xue, B.-L., Xu, F., Sun, R.-C., and Pinkert, A. (2013). "Unmasking the structural features and property of lignin from bamboo," Ind. Crop. Prod. 42, 332343. DOI: 10.1016/j.indcrop.2012.05.041

Wu, Y., Xiao, J., Wu, L., Chen, M., Xi, H., Li, Z., and Wang, H. (2014). "Adsorptive denitrogenation of fuel over metal organic frameworks: Effect of N-types and adsorption mechanisms," J. Phys. Chem. C 118(39), 22533-22543. DOI: 10.1021/jp5045817

Xiong, F., Han, Y., Wang, S., Li, G., Qin, T., Chen, Y., and Chu, F. (2017). "Preparation and formation mechanism of renewable lignin hollow nanospheres with a single hole by self-assembly," ACS Sustain. Chem. Eng. 5(3), 2273-2281. DOI: 10.1021/acssuschemeng.6b02585

Xing, J., Tao, P., Wu, Z., Xing, C., Liao, X., and Nie, S. (2019). "Nanocellulose-graphene composites: A promising nanomaterial for flexible supercapacitors," Carbohyd. Polym. 207, 447-459. DOI: 10.1016/j.carbpol.2018.12.010

Yao, S., Nie, S., Yuan, Y., Wang, S., and Qin, C. (2015). "Efficient extraction of bagasse hemicelluloses and characterization of solid remainder," Bioresource Technol. 185, 21-27. DOI: 10.1016/j.biortech.2015.02.052

Yao, S., Nie, S., Zhu, H., Wang, S., Song, X., and Qin, C. (2017). "Extraction of hemicellulose by hot water to reduce adsorbable organic halogen formation in chlorine dioxide bleaching of bagasse pulp," Ind. Crop. Prod. 96, 178-185. DOI: 10.1016/j.indcrop.2016.11.046

Yao, S., Gao, C., Wang, C., Shi, L., Qin, C, and Wang, S. (2018). "Kinetics of adsorbable organic halogen formation during chlorine dioxide bleaching of eucalyptus kraft pulp," J. Biobased. Mater. Bio. 12(2), 218-222. DOI: 10.1166/jbmb.2018.1767

Yue, F., Lu, F., Ralph, S., and Ralph, J. (2016). "Identification of 4-O-5-units in softwood lignins via definitive lignin models and NMR," Biomacromolecules 17(6), 19091920. DOI: 10.1021/acs.biomac.6b00256

Zhang, H., Nie, S., Qin, C., and Wang, S. (2019). "Removal of hexenuronic acid to reduce AOX formation in hot chlorine dioxide bleaching of bagasse pulp," Ind. Crop. Prod. 128, 338-345. DOI: 10.1016/j.indcrop.2018.11.025

Article submitted: September 26, 2018; Peer review completed: December 15, 2018; Revised version received and accepted; December 19, 2018; Published: December 21, 2018.

DOI: $10.15376 /$ biores.14.1.1265-1278 